\title{
A PROSPECTIVE OBSERVATIONAL STUDY OF ANTIBIOTIC USAGE PATTERNS AND MICROBIOLOGICAL ANALYSIS IN DIABETIC FOOT ULCER PATIENTS
}

\author{
Vinay Kumar Sankurshetty¹, Pradeep Acha², Venkateshwarlu Eggadi¹, Sheshagiri Sharvana \\ bhava Bandaru 1
${ }^{1}$ Department of Clinical Pharmacy \& Pharm.D., Vaagdevi College of Pharmacy, Kakatiya University, Warangal, Telangana-506001, India.
${ }^{2}$ Mahatma Gandhi Memorial Hospital, Warangal, Telangana, India.
*Corresponding author e-mail: sharvanabhava6@gmail.com

\begin{abstract}
:
Diabetes is a group of metabolic disorders characterized by hyperglycemia which is a result of either defects in insulin secretion, insulin action or both and diabetic foot is the feared complication of diabetes. It is characterized by several pathological complications which leads to the development of gangrene and even necessitates limb amputation. This dissertation was designed determine the bacterial profile of infected ulcers and to institute the appropriate antibiotic usage pattern. Deep wound swab was cultured from 50 diabetic foot ulcer patients. Specimen was examined by gram stain procedure, cultured and antibiotic sensitivity, resistance patterns were obtained. A total number of 39 pathogens were isolated from wound swabs. Gram negative aerobes constitutes of 33 isolates (84\%) followed by gram positive aerobes 6 isolates (16\%). Common pathogens isolated include Klebsiella, Proteus and E. Coli. Gram negative were sensitive to Amikacin, Meropenem and Cefexime. Gram positive were sensitive to Amikacin, Vancomycin and Teicoplanin. Our study concluded that Gram negative isolates are leading infectious agents from specimens. Amikacin was sensitive to Gram negative as well as Gram positive bacteria. Our study also assists the physician for the selection of appropriate antibiotics to improve the wound healing.
\end{abstract}

Key words: Diabetes mellitus, Diabetic foot ulcer, Antibiotic therapy, Microbiology analysis.

\section{INTRODUCTION:}

Globally many people are being affected with Diabetes which is a chronic disorder [1]. It is a group of metabolic disorders characterized by hyperglycemia which is a result of either defects in insulin secretion, insulin action or both [2].With nearly one million diabetic deaths every year, India turned out as the "diabetic capital of the world [3]. Prevalence of diabetes is one-quarter in rural population than urban population in India and other subcontinent countries [4]. Roughly one-fourth of people with diabetes are prone to an ulcer during their entire lifetime which may be www.ijapbjournal.com infected with microbes [5,6]. Hospitalization of diabetic people is majorly due to an infected ulcer [7]. More over microorganisms which have been identified in an infected foot differ not only patient to patient and hospital to hospital but also from one part of the country to another [8]. Most frequent pathogens contributing to progressive and widespread tissue destruction are Escherichia coli, Proteus species., Pseudomonas species., Staphylococcus aureus and Enterococcus species [9]. Casual pathways which lead to ulceration of foot include several component 
causes, of which primary cause is peripheral neuropathy. Peripheral neuropathy must be intense before leading to loss of protective sensation, the later consequences are vulnerable to physical and thermal trauma which increases the risk of foot ulceration 7 fold. Excessive plantor pressure is secondary causative factor in foot ulceration. It includes both limited joint mobility and foot deformities. Tertiary cause is trauma, predominatly when it is repetitive. People with previous foot ulceration history could resist to few cycles of stress to their feet in advance to any ulcer recurred [10]. Infectious microorganisms are associated with amputation of infected foot if not treated properly and will increase the duration of hospital stay and the cost of management as well as morbidity and mortality [11]. Foot infections in persons with diabetes are initially treated empirically, later treated according to the appropriate organism involved in causing the infection [12]. This antibiotic selection is critical in managing the health condition of the patient [13]. Aim of the present study is was to evaluate the bacteriology of diabetic foot ulcers at Mahatma Gandhi Memorial Hospital, Warangal, Telangana, in order to determine the relative frequencies of bacterial isolates cultured from foot infections and to assess the invitro antibiotic resistance and suspectibility of the isolated bacteria to a variety of commonly used antibiotics [13].

\section{MATERIALS AND METHODS}

This is a prospective observational study carried out in Mahatma Gandhi Memorial Hospital, Warangal. Institutional Human Ethics committee endorsement was seeken and obtained before conduct of trial (MGM/VCOP/PHARMD/V/011/2017).

Selection of subjects was performed according to the following inclusion and exclusion criteria. Inclusion Criteria: Patients diagnosed with Diabetes. Patients with recent and recurrent diabetic foot ulcer. Exclusion Criteria: Patients with non-diabetic foot ulcer. Statistical analyses: Tables and graphs were drawn by using MS-ACCESS to MS-EXCEL.

\section{RESULTS}

During the study period, a total number of 65 patients were approached to participate in our study, out of which 58 individuals data was taken where 50 diabetic foot ulcer patients current medical history was collected and followed up for further study. 8 patients data was not included due to several reasons (unwillingness of patient and patient has not signed the consent form). A majority of patients (46\%) having the foot ulcer are in the age group between(56-65yrs). The average age of patients is $56.08 \pm 10.31$ years. Among the 50 patients 32 patients (64\%) are from rural area who were predominant for developing foot ulcer when compared with patients $18(36 \%)$ of urban area. The duration of diabetes mellitus for below 5 years was observed in $9(18 \%)$ patients, between 5$10 y$ rs in $13(26 \%)$ patients, between $10-15$ years in $20(40 \%)$ patients and in between $15-20$ years in $8(16 \%)$ patients. The average duration of Diabetes mellitus in patients was $10 \pm 7.071$ years. The mean duration of ulcer is $16.66 \pm 21.12$ months. Most worsening infection is seen in patients with ulcer duration above one month which is shown in Table 1.

Out of 50 patients, 6 patients had recurrent ulcers and 44 patients have suffered from single ulcer exposure. 10 patients had Hypertension, 2 patients had history of Coronary artery disease, 1 patient had history of Coronary artery disease and Hypertension and 1 patient had history of Hypertension and Cardio-vascular attack. The average 
Table.1: Demographics variables among diabetic patients with recurrent ulcer and Single exposure to ulcer.

\begin{tabular}{|c|c|c|c|c|}
\hline Variables & Total No. (\%) & Single exposure (44) & Recurrent ulcer (6) & $\begin{array}{c}\text { Overall } \\
\text { Mean } \pm s d\end{array}$ \\
\hline \multicolumn{4}{|c|}{ Diabetes mellitus (yrs) } & $10 \pm 7.071$ \\
\hline$\leq 5$ yrs & $9(18 \%)$ & 9 & - & \\
\hline $5-10$ yrs & $13(26 \%)$ & 11 & 2 & \\
\hline $10-15$ yrs & $20(40 \%)$ & 17 & 3 & \\
\hline 1520 yrs & $8(16 \%)$ & 6 & 1 & \\
\hline \multicolumn{4}{|c|}{ Duration of Ulcer } & $16.66 \pm 21.12$ \\
\hline$\leq 1$ month & $41(82 \%)$ & 38 & 3 & \\
\hline $1-2$ months & $6(12 \%)$ & 4 & 2 & \\
\hline 2 months $\geq$ & $3(6 \%)$ & 2 & 1 & \\
\hline \multicolumn{4}{|l|}{ Size of ulcer } & NA \\
\hline$\leq 5 \mathrm{~cm} 2$ & $39(78 \%)$ & 35 & 4 & \\
\hline$\geq 5 \mathrm{~cm} 2$ & $11(22 \%)$ & 9 & 2 & \\
\hline
\end{tabular}

hospital stay of patients is $18.22 \pm 23.75$ days. The above results were given in Table no. 2 Patients with barefoot walking history were at high risk for developing diabetic foot ulcer. Most patients admitted were of Spontaneous ulcer development followed by Traumatic ulcer.
According to Wagner Nelson classification of Diabetic foot ulcer the extent of foot involved is assessed in Wagner grading. 2 patients are under grade 2, 10 patients are under grade 3 , 28 patients are under grade 4 and 10 patients are under grade 5 . This data was pictorially represented in Fig.no.1.

Table no.2 : Data including Hisory of ulcer, duration of hospital stay and the status of the subjects involved.

\begin{tabular}{|c|c|c|c|c|}
\hline Variables & Total No. (\%) & $\begin{array}{c}\text { Diabetic patients with } \\
\text { single exposure }(44)\end{array}$ & $\begin{array}{c}\text { Diaebticpatients } \\
\text { with recurrent } \\
\text { ulcer }(6)\end{array}$ & $\begin{array}{l}\text { Overall } \\
\text { Mean } \pm \text { sd }\end{array}$ \\
\hline History of ulcer & & & & NOT APPLICABLE \\
\hline Trauma & $20(40 \%)$ & 4 & 15 & \\
\hline Insect bite & $3(6 \%)$ & - & 3 & \\
\hline Spontaneous & $27(54 \%)$ & 2 & 25 & \\
\hline Typeof Comorbidity & & & & NOT APPLICABLE \\
\hline Hypertension & $10(20 \%)$ & 2 & 8 & \\
\hline CAD & $2(4 \%)$ & - & 2 & \\
\hline HTN and CAD & $1(2 \%)$ & - & 1 & \\
\hline HTN and CVA & $1(2 \%)$ & 1 & - & \\
\hline None & $36(72 \%)$ & 3 & 33 & \\
\hline Treatment & & & & NOT APPLICABLE \\
\hline Conservative & $41(82 \%)$ & 1 & 40 & \\
\hline Amputations & $9(18 \%)$ & 4 & 5 & \\
\hline Hospital stay & & & & $18.22 \pm 23.75$ \\
\hline$\leq 15$ days & $44(88 \%)$ & 3 & 41 & \\
\hline $15-30$ days & $5(10 \%)$ & 3 & 2 & \\
\hline$\geq 30$ days & $1(2 \%)$ & 1 & - & \\
\hline Status & & & & NOT APPLICABLE \\
\hline Discharge & $50(100 \%)$ & 6 & 44 & \\
\hline Dead & 0 & - & - & \\
\hline
\end{tabular}




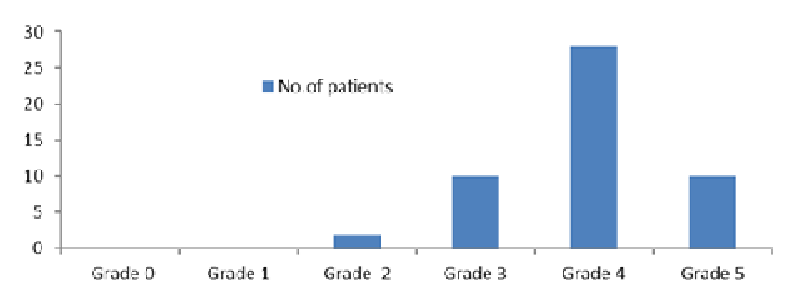

Fig.1: Wagner Nelson Classification of Diabetis Foot Ulcer

Al the 50 sample specimensarere cultured and organisms have been found in 39 specimens. Out of 39 organisms, 33 isolates showed single organism growth, remaining sample specimens showed poly-microbial growth.

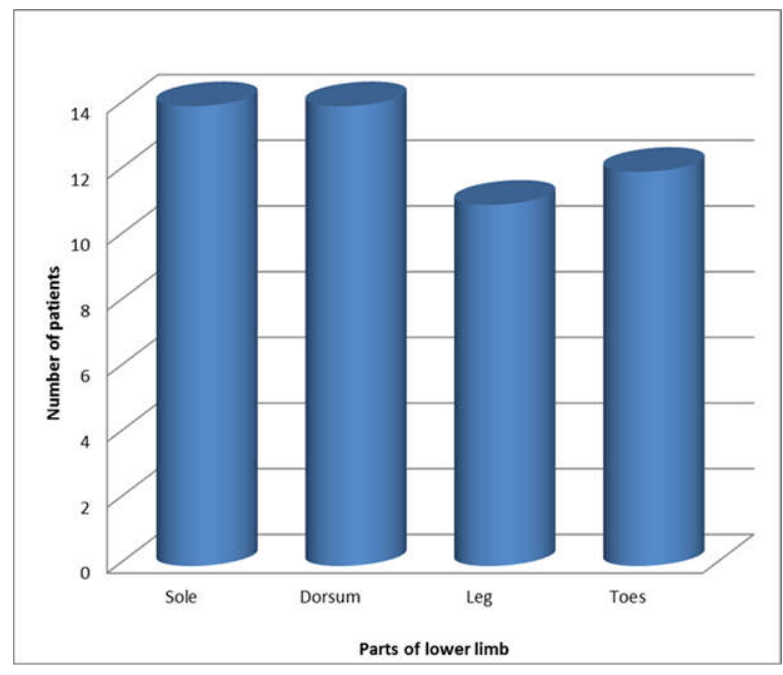

Fig.2: Showing the occurrence of Diabetic lesions in Diabetic foot ulcer patients.
In this particular study, 33 isolates were Gram negative which are predominant in nature including Klebsiella species 11(33\%), E.Coli 6(18\%), Proteus species 8(24\%), Pseudomonas species 5(15\%), Citrobacter species 3(9\%) and 6 isolates were Gram positive including Coag negative staphylococcus 4 (66.6\%) and Staphylococcus aureus $2(33.3 \%)$ which was clearly shown in Figure 3.

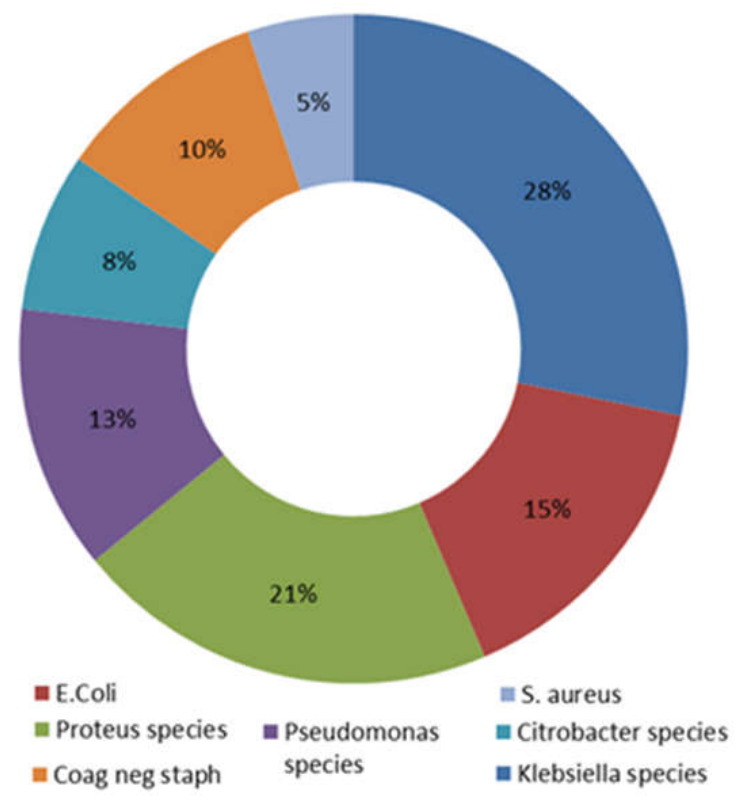

Fig. 3: Showing the Percentage of Bacterial isolates cultured from Diabetic foot ulcer patients.

Gram negative isolates like Klebsiella species were susceptible to Cefipime (63\%), Amikacin (82\%), Meropenem (63\%),

\section{Table 3: Percentage of antibiotic susceptibility in Gram negative aerobes :}

\begin{tabular}{|l|c|c|c|c|c|}
\hline \multicolumn{1}{|c|}{ Antibiotics } & $\begin{array}{c}\text { Klebsiella } \\
\text { (\%) N=11 }\end{array}$ & $\begin{array}{c}\text { E Coli } \\
\text { (\%) N=6 }\end{array}$ & $\begin{array}{c}\text { Proteus } \\
\text { (\%) N=8 }\end{array}$ & $\begin{array}{c}\text { Pseudomonas } \\
\text { (\%) N=5 }\end{array}$ & $\begin{array}{c}\text { Citrobacter } \\
\text { (\%) N=3 }\end{array}$ \\
\hline Amikacin & $9(82 \%)$ & $4(66 \%)$ & $4(50 \%)$ & $2(40 \%)$ & $2(67 \%)$ \\
\hline Oflaxacin & $4(36 \%)$ & - & - & - & - \\
\hline Meropenem & $7(63 \%)$ & $3(50 \%)$ & $6(75 \%)$ & $3(60 \%)$ & - \\
\hline Ciprofloxacin & $4(36 \%)$ & - & - & - & - \\
\hline Cefipime & $7(63 \%)$ & - & - & - & - \\
\hline Imipenem & $4(36 \%)$ & $2(33 \%)$ & - & $2(40 \%)$ & - \\
\hline Clotrimaxazole & - & $5(83 \%)$ & - & - & - \\
\hline Gentamycin & $1(9 \%)$ & - & - & - & - \\
\hline Piperacillin/ & $2(9 \%)$ & - & $2(25 \%)$ & - & \\
\hline Tazobactum & & & & & \\
\hline
\end{tabular}


Ciprofloxacin (36\%), Oflaxacin (36\%), Imipenem (36\%). Proteus species were susceptible to Meropenem (75\%), Amikacin (50\%) and Piperacillin/tazobactum (25\%). E.Coli species were susceptible to Clotrimaxazole (83\%), Amikacin (66\%), Meropenem (50\%) and Imipenem (33\%). Pseudomonas species were susceptible to Meropenem (60\%), Amikacin (40\%) and Imipenem (40\%). Citrobacter species were susceptible to Amikacin (67\%), Gentamycin (33\%) and Cefipime (37\%) was shown in Table. 3.

Table.4: Percentage of antibiotic susceptibility in Gram positive aerobes:

\begin{tabular}{|c|c|c|}
\hline Antibiotic & $\begin{array}{l}\text { S. aureus } \\
\text { (\%) } \mathrm{N}=2\end{array}$ & $\begin{array}{c}\text { Staphylococcus } \\
(\%) \mathrm{N}=4\end{array}$ \\
\hline Teicoplanin & $2(100 \%)$ & $4(100 \%)$ \\
\hline Vancomycin & $2(100 \%)$ & $4(100 \%)$ \\
\hline Amikacin & $2(100 \%)$ & $4(100 \%)$ \\
\hline
\end{tabular}

Gram positive bacteria were susceptible to Amikacin (100\%), Vancomycin(100\%) and Teicolplanin(100\%). Klebsiella species were resistant to Pipearacillin/tazobactum (63\%), Oflaxacin (45\%), Tetracycline (27\%). E.Coli species were resistant to Cefuroxime (100\%), Piperacillin/tazobactum and Tobramycin each (83\%), Tetracycline (66\%), Amoxicillin (50\%), Ampicillin/ salbactum (50\%), Cefipime (50\%). Proteus species were resistant to Oflaxacin (83\%), Amikacin (67\%), Piperacillin/ tazobactum (67\%), Cefuroxime (50\%). Pseudomonas species were resistant to Oflaxacin (100\%), Piperacillin/tazobactum (80\%), Amikacin (60\%), Augmentin (60\%), Clarithromycin (60\%). Citrobacter species were resistant to Clarithomycin (67\%), Ciprofloxacin (33\%), Meropenem (33\%).

\section{DISCUSSION}

India holds the largest number of Diabetic population and currently with 60.1million diabetic individuals. Diabetic foot infection is major cause for hospital admission of diabetic patients [15]. The current study uses the same broad survey approach as study done by Deribe et al., [16] which reveals that $64 \%$ patients are from rural area suffering from diabetic foot infection when compared to urban people $36 \%$. According to a previous dissertation extended spectrum antimicrobial therapy may delay the improvement of the Diabetic foot infection due to resistance to the antimicrobial therapy [17]. Present study reported that the small spectrum antibiotic therapy is effective to avoid the development of the resistant organisms.

In this study, a total number of 39 organisms were isolated from 50 samples with an average of 1.28 per case as similar to previous study which yielded an average of 1.21 organisms per case and slightly lower than the findings from another report which yielded an average of 1.52 per case $[18,19]$.

Our findings were similar to some studies which yielded that, mild diabetic foot infections are mostly monomicrobial, where as severe and moderate diabetic foot infections are polymicrobial.[13,15]A report submitted by Dhanasekaran et al., in 2003, have yielded that about $84 \%$ of diabetic foot ulcers were monomicrobial, which was similar to our study findings.[20] Gram negative bacteria were the predominant species with $84.6 \%$ and Gram positive with 15.3\% cases. Among 30 isolates, 26 were Gram negative and 4 were Gram positive which is similar to Indian studies $[10,18]$. Gram negative bacteria are predominant cause for infections which is similar to reports from similar studies. [21, 22]. Klebsiella and Proteus were the leading organisms under Gram negative bacteria in this present study. Ramani et al. [23], made slightly similar observation and majority of Proteus (20.73\%), Klebsiella (12.35\%) as the 
most common pathogens. Klebsiella species exhibited sensitivity to Amikacin (82\%), Ciprofloxacin (36\%) Imipenem (36\%) and Piperacillin/Tazobactam(9\%) accordingly. Proteus showed sensitivity to Meropenem (75\%), Amikacin (50\%) and Piperacillin/ Tazobactam (25\%). E.coliis sensitive to Clotrimaxazole (83\%), Amikacin (66\%), Meropenem (50\%) and Imipenem (33\%). Gram positive bacteria showed sensitivity to Amikacin, Vancomycin and Teicoplanin. Amikacin was effective against Gram positive and Gram-negative isolates as similar to previous observation [15,9]. A study conducted by Umadevi et al., reported that Amikacin, Piperacillin/tazobactum and Imipenem were sensitive against Gram negative bacteria [24]. This present scenario distinguished from a study in Chennai that they reported E.Coli showed 100\% sensitivity to Imipenem and Meropenem and they are resistant against Gentamycin [25]. Our study reported that E.Coli exhibited (83\%) sensitivity to Clotimaxazole, (75\%) to Meropenem and (33\%) to Imipenem.

In accordance to resistance pattern, Klebsiella species were resistant to Piperacillin/ tazobactum (63\%), Oflaxacin (45\%), Clarithromycin (18\%). Proteus species were resistant to Oflaxacin (83\%), Pipercillin/ tazobactum (67\%) and Amikacin (67\%). E.Coli was resistant to Cefuroxime (100\%), Pipercillin/tazobactum (83\%), Tobramycin (83\%) and Tetracycline (66\%). Citrobacter species showed resistance to Claritromycin (67\%), Meropnem (33\%) and Ciprofloxacin (33\%). Gram positive bacteria are resistant to Ampicillin/salbactum.

\section{CONCLUSION}

Our study concluded that Gram negative isolates are leading infectious agents from specimens. Amikacin was sensitive to Gram negative as well as Gram positive bacteria.
Gram negative bacteria are less sensitive to Cefipime, Meropenem, Imipenem, Ciprofloxacin and resistant to Piperacillin/ Tazobactum, Oflaxacin, Cefuroxime and Tetracycline. Our study assists physician for the selection of proper antibiotics to improve the wound healing and also helps to avoid the irrational antibiotic usage by Institutional antibiotic committee. From our findings, we concluded that the decrease in Multi drug resistance improves the wound healing, there by improves the patients Quality of Life which is helpful for further studies. Our study found that rural Diabetic patients having the bare foot walking history were more prone to develop injuries that may lead to Diabetic foot ulcer.

\section{ACKNOWLEDGEMENT}

Authors are grateful to the Secretary, Dr. Ch. Devender Reddy, Viswambhara Educational society, for giving us occasion to work and giving essential offices to complete this Research work.

\section{CONFLICT OF INTEREST}

The author(s) confirm that this article content has no conflict of interest.

\section{AUTHORS CONTRIBUTION}

Anila Reddy $\mathrm{T}$ worked in the Hospital in assortment of information, Counseling the patient and their family, and so on, Vineeth Reddy G planned the records needed for the work. Sharavana bhava B.S. talked about and considered accomplishing this work and arranged the Protocol.

\section{REFERENCES}

[1] Sivanmaliappan TS, Sevanan M. Antimicrobial susceptibility patterns of Pseudomonas aeruginosa from diabetes patients with foot ulcers. Int J Microbiol 2011: 2011:605195, 2014 
Sankurshetty et al.

[2] Ahmed AM , History of diabetes mellitus. Saudi Med J 23: 373-378, 2002.

[3] CharithaKaithalaet al. Prevalence of Dyslipidemia and its association with glycemic control in Indian type 2 diabetes population. Rom J Diabetes NutrMetab Dis. 23(3):277-283, 2016.

[4] 4.Seema Abhijeet Kaveeshwar, Jon Cornwall. The current state of diabetes mellitus in India. Australas Med J. 2014; $7(1)$ : 45-48.

[5] 5. Lipsky BA, Berendt AR, Deery HG, Embil JM, Joseph WS, Karchmer AW et al. Diagnosis and treatment of diabetic foot infections. Clin Infect Dis 39:885-910, 2004.

[6] Lavery LA, Armstrong DG, Murdoch DP, Peters EJ, Lipsky BA. Validation of the Infectious Diseases Society of America's diabetic foot infection classification system.Clin Infect Dis44:562-565, 2007.

[7] Lavin ME and O'Neal LW, The diabetic foot. St. Louis: CW Mosby Co. 203-205, 1998.

[8] 8.El-Tahawy AT. Bacteriology of diabetic foot infections. Saudi Medical J 21:344$347,2000$.

[9] AnandiC, Alaguraja D, Natarajan V, Ramanathan M, Subramaniam CS, Thulasiram M, et al. Bacteriology of diabetic foot lesions. Indian $J$ Med Microbiol, 22: 175-8, 2004.

[10] Gadepalli R,Dhawan B, Sreenivas V, Kapil, Ammini AC ,Chaudhry R , A clinicomicrobiological study of diabetic foot ulcers inan Indian tertiary care hospital. Diabetes Care29: 1727-32, 2006.

[11] K.Bakker,,J. Apelqvist,N. C. Schaper, Practical gudielines on the management and prevention of the diabetic foot 2011,
Int. J. Adv. Pharm. Biotech., 2017; 3(4):5-12 doi.org/10.38111/ijapb.20170304002

Diabetes Metab Res Rev 2012; 28:225231.

[12] Hartemann-Heurtier A, Robert J, Jacqueminet S, Ha VG, Golmard JL, Jarlier $\mathrm{V}$ et al. Diabetic foot ulcer and multidrugresistant organisms: risk factors and impact. Diabet Med 21:710-715, 2004.

[13] Citron DM, Goldstein EJC, Merriam VC, Lip sky BA, Bacteriology of moderate to severe diabetic foot infections and invitro activity of antimicrobial agents $J$ Clin Microbiol, 45(9):2819-28, 2007.

[14] Michele. et al., (2015). Aerobic bacterial profile and antibiotic resistance in patients with diabetic foot infection: Revista da Sociedade Brasileria de Medicina Tropical, 48(5): 546-554, 2015.

[15] 15. Sharma, V.K., K.P. Common pathogens isolated in diabetic foot infection in Bir Hospital. Kathmandu Univ. Med. J., 4(3): 295-301, 2006.

[16] Deribe. et.al.. Prevalence and Factors Influencing Diabetic Foot Ulcer among Diabetic Patients Attending Arbaminch Hospital, South Ethiopia. J Diabetes Metab, 2: 322, 2014.

[17] Diekema. et.al., Concordance of nasal and diabetic foot ulcer staphylococcal colonization. Diagn Microbiol Infect Dis, 79(1):85-9, 2014.

[18] Vishwanathan. et.al, The diabetic foot in Africa and India. International Diabetes Monitor 19: 1, 2007.

[19] Bansal. et.al,. Spectrum of microbial flora in diabetic foot ulcers. Indian J. Pathol. Microbiol.,51: 204, 2008.

[20] Dhanashekaran et.al., Microbial pattern of soft tissue infections in diabetic patients in South India. Asian J. Diabet., 5: 8-10, 2003. 
Sankurshetty et al.

[21] Zubair., et. al., Diabetic foot ulcer: A review., American Journal of Internal Medicine 3(2): 28-49, 2015.

[22] Prabhakar.et.al., Bacteriological study of diabetic foot ulcers, Trop Geogr Med. 33(3):249-52, 1981.

[23] Ramani.et.al., Bacteriology of diabetic foot ulcers, Indian Journal of Pathology and Microbiology34(2):81-7, May 1991.
Int. J. Adv. Pharm. Biotech., 2017; 3(4):5-12 doi.org/10.38111/ijapb.20170304002

[24] Umadevi.et.al., Microbiological study of diabetic foot infections., Indian Journal of Medical Specialities;2(1):12-17, 2011.

[25] Murugan.et.al., Rifampicin resistance among multi-resistant MRSA clinical isolates from Chennai, India, and their molecular characterization., Genetics and Molecular Research 14 (1):2716-2725, 2015.

\section{How to cite this article:}

Sankurshetty et al A Prospective Observational Study of Antibiotic Usage Patterns and Microbiological Analysis In Diabetic Foot Ulcer Patients. Int. J. Adv. Pharm. Biotech., 2017; 3(4): 5-12. 